\title{
Solubility Modeling of N-CBZ Derivatised Amino Acids in Supercritical Carbon Dioxide
}

\author{
N. Vedaraman1, Pravin Gadkari'2,3, Balaraman Manohar ${ }^{2,3}$, K. V. Sandhya1, \\ Gerd Brunner ${ }^{4}$ K. Udaya Sankar ${ }^{2 *}$ \\ ${ }^{1}$ CSIR-Central Leather Research Institute, Chennai, India \\ ${ }^{2}$ Food Engineering, CSIR-Central Food Technological Research Institute, Mysore, India \\ ${ }^{3}$ Academy of Scientific and Innovative Research, CSIR-CFTRI, Mysore, India \\ ${ }^{4}$ VT-2, TUHH, Hamburg, Germany \\ Email: udayaskadimi@gmail.com
}

Received 28 April 2014; revised 27 May 2014; accepted 19 June 2014

Copyright (C) 2014 by authors and Scientific Research Publishing Inc.

This work is licensed under the Creative Commons Attribution International License (CC BY).

http://creativecommons.org/licenses/by/4.0/

c) (i) Open Access

\section{Abstract}

The experimental solubility of CBZ (Carbobenzoxy) derivatized amino acids namely N-CBZ valine, $\mathrm{N}$-CBZ proline, N-CBZ aspartic acid in supercritical carbon dioxide were correlated by Soave-Redlich-Kwong Equation state based on fugacity determination and group contribution method using extrapolated critical parameters and mixing rules and other two different empirical models proposed by Yu (1994) and Gordillo-coworkers (1999). The SRK EOS prediction showed very high deviation of \% AARD of $9 \%-59 \%$. The Yu model had three derivatized amino acids with average absolute deviation from 2.04, 8.17, 10.96, while the Gordillo model had $0.245,1.067$ and 1.144 for CBZ-valine, CBZ-proline and CBZ-aspartic acid successively. The correlated values had better fit with Gordillo model. The predictive capability and applicability for these amino acid derivatives for both the models demonstrated with correlation coefficient around 0.99 for all the experimental solubility observed.

\section{Keywords}

Derivatized Amino Acids, Soave-Redlich-Kwong (SRK), Yu Model, Gordillo Model

\section{Introduction}

Growing concern on the adverse environmental impact in industrial processing, stringent legislation on the solvent residues in food extracts or products, growing demand by the consumers as well as the processors for safe

"Corresponding author.

How to cite this paper: Vedaraman, N., Gadkari, P., Manohar, B., Sandhya, K.V., Brunner, G. and Udaya Sankar, K. (2014) Solubility Modeling of N-CBZ Derivatised Amino Acids in Supercritical Carbon Dioxide. International Journal of Analytical Mass Spectrometry and Chromatography, 2, 52-63. http://dx.doi.org/10.4236/ijamsc.2014.22006 
and products, new modes of production processes are intensely pursued in the industry for the past two decades. One of the major processing technologies that are increasingly applied in industry are high pressure technology based on the use of supercritical $\mathrm{CO}_{2}$ processes for extraction, sorption process, chromatography, drying, nucleation, membrane separation, encapsulation, impregnation, biochemical reactions and chemical reactions [1][3]. Supercritical fluids came into the fore front in view of their properties that help favorable mass transfer properties, such as high diffusivities and compressibility's gas like tending to liquid, liquid like densities and no surface tension, variable solvent power based on tuning the pressure and temperature that help in selective separation due to variable solute solubility [4] [5]. Supercritical carbon dioxide is the solvent of choice in view of the fact the critical temperature $\left(31.2^{\circ} \mathrm{C}\right)$ is near ambient, non-toxic, non-inflammable, inexpensive and used soft drinks for carbonation as GRAS substance [1].

In chemical process whether it is a separation or reaction, the experimental solubility of the solute in the reaction media, say carbon dioxide (SCF solvent) is very essential. Although innumerable studies on solubility had taken place [6], still there is a dearth for solubility data on compounds in supercritical fluids. Wherever there is a solubility data to extrapolate to the different conditions, it is necessary model the solubility data based on thermodynamic equation of state that needs the critical properties of the solutes, acentric factors, vapour pressure data, density data of solute in gas, liquid and solid phases, and density of mixtures. For most of the biological activity compounds such data is not available and need to extrapolated either by group contribution methods. Sometimes, it is better follow empirical models to fit the experimental data for extrapolation in waste and process engineering [7].

Slaughter house and tannery wastes such as poultry feathers, animal flesh, hair, horn, and hoof are major source of environmental pollution and receiving much attention for researchers. These protein waste materials can be subjected to acid or alkali hydrolysis and extract to obtain different aminoacids in purer form. But the separation of amino acids using supercritical fluids hindered due to their poor solubility due to their polar nature. The amino acids are derivatised to carbozoxybenzene to enhance their solubility in supercritical carbon dioxide [8]. By derivatisation of the amino acids, where the both the polar groups such as amino and carboxylic acid groups are blocked, the solubility is further enhanced for ease of separation and purification in supercritical carbon dioxide.

There are several empirical models projected in past decade such as Mendez-Santiago-Teja, Modified Mendez-Santiago-Teja, Bartle, Yu, Charstil, and Gordillo model, which gives good promise with experimental data over wide range of temperature and pressure [9]-[13]. The easiest way of correlating solubility data is empirical fit where the relationship between thermodynamic property such as pressure and density can be fitted and presented linearly. Basically there are three types of models namely solubility parameter model, density and chemical association semi-empirical models [7]. Some commonly used equation of states that help the modeling of solubility parameter model are Soave-Redlich-Kwong equation of state, Peng-Robinson equation of state, and Lee-Kesler-Plocker equation of state. These equations of state are more complicated than empirical or semiempirical model, because it requires more efforts to figure out the unknown constants such as critical temperature, critical pressure, critical volume and acentric factors in the model. Also the solute properties are not available for complex structures such as some proteins and amino acids in which complicated computational prediction and group contribution methods are involved [14].

The present study is aimed at correlation of the solubility of the N-CBZ amino acids carried out by Vedaraman et al. (2004) using 1) Soave Redlich-Kwong equation and empirical models developed by 2) Yu et al. (1994) and 3) Gordillo et al. (1999).

\section{SRK EOS Based Correlation and Prediction of Solubility CBZ N-Amino Acids}

Soave-Redlich-Kwong thermodynamic model for correlating the solubility of solutes at high pressures by appropriate corrections for volume of the gas and appropriate mixing rules. It involves the data on critical properties of both the solvent and the solute, determination of mixed parameters using appropriate mixing rules [15].

The critical temperature $\left(T_{c}\right)$ and the critical pressure $\left(P_{C}\right)$ of the CBZ-N-amino acids determined by Lyderson's critical property group contribution increments based on chemical structure was used [16].

$$
T_{C}=T_{B} /\left[0.567+\sum \Delta T_{L}-\left(\sum \Delta T_{L}\right)^{2}\right]
$$


where $T_{B}=$ Normal Boiling temperature, $\theta=T_{B} / T_{C}$

$$
\beta=\frac{\left[(1-\theta)^{2 / 7}-0.048 \operatorname{In} V_{C}+(1-\theta)^{2 / 7} \operatorname{In} P_{c}+1.225\right]}{(1-\theta)^{2 / 7}}
$$

$\Delta T_{L}=$ Group Contributions for temperature in Lydersen Equation (2.1);

$M_{w}=$ molecular weight of the compound.

The following Equation (2.3) was used for predicting critical pressure based on group contribution methods. Lydersen

$$
P_{C}=M_{w} /\left(0.34+\sum \Delta P_{L}\right)^{2}
$$

For calculatin the acentric factor, $\omega$, Lee-Kesler Equation (2.4) was used

$$
\omega=\frac{-\operatorname{In} P_{c}-5.92714+6.09648 \theta^{-1}+1.28862 \operatorname{In} \theta-0.169347 \vartheta^{6}}{15.2518-15.6875 \theta^{-1}-13.4721 \operatorname{In} \theta+0.43577 \theta^{6}}
$$

The critical volume is extrapolate by Lydersen group contribution methods

$$
V_{C}=40+\sum \Delta V_{L}
$$

$\Delta V_{L}=$ Group Contributions for volume in Lydersen Equation (2.5).

Generally measurements of boiling points are made at lower pressures for extremely high boiling compounds or for compounds that decompose (especially true for bio-active components such as bakuchiol) before they boil at atmospheric pressure [17]. Joback used the same approach to develop a method for normal boiling point as he used to develop a method for critical temperature. The resulting method is a function of structure only. The Joback's equation for calculating the boiling point is shown below:

$$
T_{B}=198+\sum \Delta B_{J}
$$

where $\Delta B_{J}=$ Group Contributions for boiling point.

The vapor pressure is the pressure exerted by a pure component at equilibrium at any temperature when both liquid and vapor phases exist and thus extends from a minimum at the triple point temperature to a maximum at the critical temperature, the critical pressure.

In the present study to calculate vapour pressures, the Equations (2.7) to (2.76) were adopted from studies of Edalat and Bozar-Jomehri [18]. The method is claimed to be accurately predicting vapor pressure of hydrocarbons, non-hydrocarbons and polar fluids using only $P_{c}, T_{c}$ and $\omega$, the acentric factor. The equation is described below:

$$
\operatorname{InP} P_{r}^{s}=\left[\eta_{1} \tau+\eta_{2} \tau^{1.5}+\eta_{3} \tau^{3}+\eta_{4} \tau^{6}\right][1-\tau]^{-1}
$$

where,

$$
\begin{gathered}
\eta_{1}=-6.1559-4.0855 \omega \\
\eta_{2}=1.5737-1.540 \omega-4.43565 \times 10^{-3} \eta_{4} \\
\eta_{3}=-0.8747-7.8874 \omega \\
\eta_{4}=\left[-0.4893-0.9912 \omega-3.1551 \omega^{2}\right]^{-1} \\
\tau=1-T_{r} \\
\omega=\left(-\log P_{r}^{s}\right)_{T_{r=0.7}}-1
\end{gathered}
$$

where $P_{r}^{s}=$ reduced vapor pressure $\left(P^{s} / P_{c}\right) . \eta_{1}, \eta_{2}, \eta_{3}, \eta_{4}=$ constants defined in Equations (2.71) to (2.76).

Equations of state are used to describe the thermodynamic states through the relationship of state parameters 
such as temperature, pressure, and volume. In SCFE processing, EOS describes the behavior of solute being dissolved in supercritical fluids. The solubility of a substance (component 2) in a supercritical fluid (component 1) can be obtained from fluid-solid phase equilibria. The subscripts 1 and 2 in the following derivations denote components $\mathrm{CO}_{2}$ and solute. At equilibrium, the fugacities of the components in the solid and gas phases are equal, i.e.

$$
f_{2}^{s}\left(P, T, x_{2}\right)=f_{2}^{V}\left(P, T, y_{2}\right)
$$

where $f_{2}^{s}$ is the fugacity of solute in the solid phase; $f_{2}^{v}$ fugacity of solute in the gas phase; $P$ is the pressure; $T$ is the temperature; $x$ and $y$ are mole fractions.

If the gas component 1 is assumed to be insoluble in solid phase (true in most of the cases), then

$$
\begin{gathered}
y_{2} \varphi_{2} P=P_{2}^{\text {sat }} \varphi_{2}^{\text {sat }} \exp \int_{P \leq 1}^{P}\left(\left(V_{2}^{s} \mathrm{~d} P / R T\right)\right) \\
f_{2}^{v}=P y_{2} \varphi_{2}^{y}
\end{gathered}
$$

where, $\varphi$ is the fugacity coefficient; $V$ molar volume; $R$ is the universal gas constant; superscripts $s$ and sat denote solid and saturated conditions respectively.

From above equations, one can obtain:

$$
\begin{gathered}
y_{2}=E\left(P_{2}^{\text {sat }} / P\right) \\
y_{2}=P_{2}^{\text {sat }} \exp \left(P v_{2}^{s} / R T\right) /\left(\varphi_{2}^{v} P\right)
\end{gathered}
$$

where, $E$ is the enhancement factor which is the ratio of the solubility of the solute in super critical fluid to the solubility in an ideal gas. i.e. $E=y_{2} / y_{\text {ideal }}$

Large enhancement factors of the order of $10^{5}$ to $10^{7}$ are frequently observed due to small values of $\varphi_{2}^{v}$. $\varphi_{2}^{\text {sat }}$. $v_{2}^{s}$ can be easily calculated from the density of component 2 . Thus, to calculate E, one requires the value of $\varphi_{2}^{v}$. From well-known equation of state (EOS) available such as Peng-Robinson (PR) and Soave-Redlich-Kwong (SRK) models, $\varphi_{2}^{v}$ can be calculated.

A general form of the SRK equation is:

Soave-Redlich-Kwong equation of state (SRK-EOS) is:

$$
P=(R T /(V-b))-\left(a /\left(V^{2}+b V\right)\right)
$$

The above can also be written as:

$$
Z^{3}-Z^{2}+\left(A-B-B^{2}\right) Z-A B=0
$$

The above equation leads to:

$$
\operatorname{In} \varphi_{2}^{v}=b_{2}(Z-B) / b-\operatorname{In}(Z-B)-[A / B]\left\{2\left(a_{22} y_{2}+a_{12} y_{1} / a\right)-\left(b_{2} / b\right)\right\} \cdot \operatorname{In}(1+(B / Z))
$$

where

$$
\begin{gathered}
Z=P V / R T \\
A=a P /\left(R^{2} T^{2}\right) \\
B=b P / R T
\end{gathered}
$$

$a=$ intermolecular attraction parameter;

$b=$ covolume parameter.

\section{Mixing Rules for SRK EOS}

When the equation is extended to mixtures, the following mixing rule is employed:

$$
\begin{aligned}
a & =\sum \sum y_{i} y_{j} a_{i j} \\
b & =\sum \sum y_{i} y_{j} b_{i j}
\end{aligned}
$$


where $a_{i j}$ and $b_{i j}$ are calculated from combining rules:

$$
\begin{gathered}
a_{i j}=\left(a_{i i} a_{j j}\right)^{0.5}\left(1-k_{i j}\right) \\
b_{i j}=\left(b_{i i} b_{j j}\right)^{0.5}\left(1-n_{i j}\right)
\end{gathered}
$$

where, $k_{i j}$ and $n_{i j}$ are the adjustable binary interaction parameters. The adjustable parameters are determined by regressing phase equilibrium data and assumed to be independent of temperature, pressure and composition. It may be noted that these parameters can take negative values and accordingly, the software program should be allowed to adjust these values suitably. Many authors have used single binary interaction parameter $k_{i j}$ in their works. However, a second adjustable mixture parameter $n_{i j}$ is also used in the present study, since $n_{i j}$ can account for the large size disparity between a heavy non-volatile solute and a light SCF solvent [19]. For pure components, " $a$ " and " $b$ " parameters are calculated from critical constants $T_{c}, P_{c}$ and acentric factor, $\omega$ depending on the type of EOS.

For SRK-EOS,

$$
\begin{gathered}
a_{i}=0.42748\left(R^{2} T_{c}^{2} / P_{c}\right) \alpha \\
\alpha=\left[1+K\left(1-T_{r}^{0.5}\right)\right]^{2} \\
K=0.48+1.57 \omega-0.17 \omega^{2} \\
b_{i}=0.08664\left(R T_{C} / P_{C}\right)
\end{gathered}
$$

The computer program obtains the optimum $k_{i j}$ and $n_{i j}$ value by simple optimization technique which gives minimum average absolute relative deviation (AARD) between experimental and calculated values of solubility:

$$
\text { AARD, } \%=(1 / N) \sum\left(y_{\text {exp }}-y_{\text {cal }}\right) \cdot 100 / y_{\text {exp }}
$$

where $N$ is the number of experiments, $y_{c a l}$ and $y_{\text {exp }}$ are the calculated and experimental solubility of solute components respectively.

Experimental solubility is calculated from the slopes of the initial linear portion of extraction curve of total extract versus $\mathrm{CO}_{2}$ consumed [20]. When the extract is assumed as a single pseudo-component, the $T_{C}, P_{C}, \omega$, $P^{\text {sat }}$ of the extract is considered to be sum of the property of the main components multiplied by mole fraction of main components.

The entire calculation procedure [21] described above can be summarized as below:

1) The critical values $T_{c}, P_{c}$ and acentric factor for each component are estimated by group contribution methods.

2) Pure component parameters of the SRK-EOS are estimated.

3) $k_{i j}$ and $n_{i j}$ are assumed initial values. Then $a$ and $b$ for mixture are calculated based on mixing rules.

4) The cubic equation of state is solved for $Z$.

5) $\varphi_{2}^{v}$ is calculated.

6) $y^{2}$ is calculated.

7) Steps 2 to 6 repeated for each pressure. AARD is then calculated. If AARD is not within tolerance limit set by the program, the procedure is repeated so that one obtains the optimal $k_{i j}$ and $n_{i j}$ parameters.

A program is written in Fortran 77 incorporating the above steps to calculate the solubility with minimum deviation.

\section{Empirical Model Developed by Yu et al. [11]}

Yu et al. developed an empirical model where the solubility as a function of pressure and temperature using quadratic equation. The solubility of methyl esters, ethyl esters, fatty acids, triglycerides, and fats and oils were studied over a range of temperature and pressures. The solubility data from the literature were correlated using the Peng-Robinson equation of state and mixing rules of van der Waals (VDW) and Panagiotopoulos and Reid. The triglyceride solubility in turn found to be in terms chain length, degree of unsaturation and function groups influence the solubility in supercritical carbon dioxide. An empirical equation in turn developed to fit better for large fatty acids, fatty acid esters and triglyceride molecules as a function of the pressure and temperature. 


$$
y_{2}=C_{0}+C_{1} P+C_{2} P^{2}+C_{3}\left(1-y_{2}\right)+C_{4} T+C_{5} T^{2}
$$

\section{Empirical Model Developed by Gordillo and Coworkers [13]}

Gordillo and coworkers developed logarithmic function of the solubility equation as function of temperature and pressure of the system for Pencillin G in supercritical carbon dioxide and they used a dynamic flow apparatus for the solubility measurement of Pencillin G at pressures from 100 to 350 bar and temperature 313.5 to 333.15 K [13] Physical and Critical properties of Pencillin G were extrapolated by group contribution methods using Fedor's and Ambrose's and correlated with EOS by Redlich-Kwong and Soave modified Redlich-Kwong with Lorent-Berthelot mixing rules. A second order empirical model to correlate solubility with temperature and pressure as logarithmic function, the same empirical model has been used in the correlation of solubility of the derivatized amino acids.

$$
\text { Iny }_{2}=D_{0}+D_{1} P+D_{2} P^{2}+D_{3} P T+D_{4} T+D_{5} T^{2}
$$

\section{Results and Discussion}

Table 1 provides the experimental solubility of N-CBZ amino acids in supercritical carbon dioxide as determined by Vedaraman et al. [8]. Compared to underivatised amino acids, the solubility of N-CBZ valine, proline and aspartic acid in supercritical carbon dioxide has showed increase, in the range of $10^{-4}$ mole fraction which is quite high. Table 2 provide the critical parameters of the carbon dioxide and the N-CBZ-Valine, Proline and Aspartic acid, the critical pressure is found to be less around 22 - 24.65, while the critical temperature as observed

Table 1. Experimental solubility data of the N-CBZ derivatized amino acids in supercritical carbon dioxide (Vedaraman et

\begin{tabular}{|c|c|c|c|c|}
\hline \multirow{2}{*}{$\begin{array}{c}\text { Pressure } \\
\text { (bar) }\end{array}$} & \multirow{2}{*}{$\begin{array}{c}\text { Temperature } \\
\text { (K) }\end{array}$} & \multicolumn{3}{|c|}{ Mole fraction $\left(\times 10^{-4}\right)$} \\
\hline & & $\begin{array}{l}\text { N-CBZ } \\
\text { Valine }\end{array}$ & $\begin{array}{l}\text { N-CBZ } \\
\text { Proline }\end{array}$ & $\begin{array}{c}\text { N-CBZ } \\
\text { Aspartic acid }\end{array}$ \\
\hline 180 & 313 & & & \\
\hline 180 & 323 & & 1.1 & \\
\hline 180 & 333 & & 1.95 & \\
\hline 180 & 343 & & & \\
\hline 200 & 313 & 0.675 & & \\
\hline 200 & 323 & 0.82 & 1.35 & 0.7 \\
\hline 200 & 333 & 1.246 & 2.25 & 0.8 \\
\hline 200 & 343 & & 3.1 & 1.3 \\
\hline 220 & 313 & 0.88 & & \\
\hline 220 & 323 & 1.242 & 2.2 & 0.85 \\
\hline 220 & 333 & 1.675 & 3.5 & 1.85 \\
\hline 220 & 343 & & 4.1 & 2.65 \\
\hline 240 & 313 & 1.13 & & \\
\hline 240 & 323 & 1.525 & 4.055 & 1.15 \\
\hline 240 & 333 & 2.12 & 5 & 2.9 \\
\hline 240 & 343 & & 5.25 & 3.8 \\
\hline 260 & 313 & 1.375 & & \\
\hline 260 & 323 & 1.95 & 5.2 & 1.35 \\
\hline 260 & 333 & 2.55 & 5.95 & 3.95 \\
\hline 260 & 343 & & 6.5 & 4.8 \\
\hline 280 & 313 & 1.625 & & \\
\hline 280 & 323 & 2.235 & & \\
\hline 280 & 333 & 2.875 & & \\
\hline 280 & 343 & & & \\
\hline
\end{tabular}
al. 2004). 
are high $>900 \mathrm{~K}$, while temperature of boiling 700 - $800 \mathrm{~K}$ as predicted by group contribution methods, while at these temperatures, these compounds undergo to vapour states. The acentric factors are high when compared to most of the normal compounds as they tend to be more polar. The $P_{\text {sat }}$ is very low and it is in the of order $10^{-12}$ moles, while solubility is observed of the order $10^{-5}$ moles, showing solubility enhancements of the order of $10^{6}$ to $10^{7}$ per mole of carbon dioxide is of several thousands. The soave modified Redlich-Kwong equation of state based prediction using the mixing rules correlated with \% AARD 9\% - 65\%, while the CBZ-N-valine showed the highest \% AARD, while the $k_{i j}$ value are 0.44 to 0.46 (Table 3).

Table 4 provide the coefficients of the Equation (4.1) of the various parameters of correlated solubility of the derivatized CBZ-N-amino acids as predicted using the excel software (excel version 2010 MS Office 2010), the \% AARD as calculated by the Equation (3.2) for CBZ-N-Valine is 2.04, while the regression statistical analysis showed the R square 0.989 , standard error of $4.06 \mathrm{E}-05$ and F significance is $5.57 \mathrm{E}-05$, the p-values of the coefficient for all the parameters is less than 0.05 showing strong significance for all the coefficients except for PT(1-y) is higher showing less significance. In case of N-CBZ-proline, the \% AARD is 8.17, while statistical analysis showed the $\mathrm{R}^{2}$ is 0.989 , standard error $3.23 \mathrm{E}-05$, and F significance $2.06 \mathrm{E}-06$, the $\mathrm{p}$-values of all the coefficients is less than 0.05 showing strong significance of fit for all the coefficients. For N-CBZ-Aspartic acid, the \% AARD is 10.96 , the $\mathrm{R}^{2}$ is 0.989 , standard error $2.74 \mathrm{E}-05$ and $\mathrm{F}$ significance $5.57 \mathrm{E}-05$, the $\mathrm{p}$-values of the coefficients is less than 0.05 showing strong statistical significance of fit. The Figure 1 shows the graphical fit of solubility with different pressures and temperatures for N-CBZ-valine, proline and aspartic acid.

Table 2. Critical Properties of carbon dioxide the derivatized amino acids obtained by group contribution methods based on Lyderson, volume properties by Vetere group contribution methods, accentric factor by Lee-Kesler equation.

\begin{tabular}{ccccc}
\hline Component & $\begin{array}{c}\text { Critical Pressure } \\
\left(\boldsymbol{P}_{\boldsymbol{c}}, \mathbf{b a r}\right)\end{array}$ & $\begin{array}{c}\text { Critical Temperature } \\
\left(\boldsymbol{T}_{\boldsymbol{c}}, \mathbf{K}\right)\end{array}$ & $\begin{array}{c}\text { Boiling Temperature } \\
\left(\boldsymbol{T}_{\boldsymbol{b}}, \mathbf{K}\right)\end{array}$ & $\begin{array}{c}\text { Acentric factor, } \\
\boldsymbol{\omega}\end{array}$ \\
\hline Carbon dioxide & 72.8 & 304.1 & 194.8 & 0.225 \\
N-CBZ valine & 22.36 & 912.01 & 717.82 & 1.213 \\
N-CBZ proline & 24.09 & 907.27 & 701.23 & 1.073 \\
N-CBZ aspartic acid & 24.65 & 999.95 & 802.56 & 1.535 \\
\hline
\end{tabular}

Table 3. Parameters for SRK EOS for correlation of solubility of carbon dioxide and the derivatized amino acids at different temperatures.

\begin{tabular}{|c|c|c|c|c|c|c|c|}
\hline Component & Temp, K & A & B & $\begin{array}{l}\text { Molar volume } \\
\text { (cc/g· mol) }\end{array}$ & $\boldsymbol{P}_{\text {sat }}$ & $k_{i j}$ & $\%$ AARD \\
\hline \multirow{5}{*}{$\mathrm{CO}_{2}$} & 313.16 & $3.559 \times 10^{6}$ & 29.615 & & & & \\
\hline & 323.16 & $3.464 \times 10^{6}$ & 29.616 & & & & \\
\hline & 333.16 & $3.372 \times 10^{6}$ & 29.616 & & & & \\
\hline & 343.16 & $3.282 \times 10^{6}$ & 29.616 & 737.6 & & & \\
\hline & 313.16 & $3.792 \times 10^{8}$ & 289.91 & 780.9 & $5.155 \times 10^{-12}$ & 0.444 & 48.35 \\
\hline \multirow[t]{3}{*}{ CBZ-N-Valine } & 323.16 & $3.713 \times 10^{8}$ & 289.91 & 780.9 & $2.679 \times 10^{-11}$ & 0.448 & 57.78 \\
\hline & 333.16 & $3.636 \times 10^{8}$ & 289.91 & 780.9 & $1.243 \times 10^{-10}$ & 0.445 & 59.25 \\
\hline & 343.16 & $3.036 \times 10^{8}$ & 267.75 & 737.6 & $4.121 \times 10^{-9}$ & 0.454 & 9.08 \\
\hline \multirow[t]{3}{*}{ CBZ-N-Proline } & 333.16 & $3.098 \times 10^{8}$ & 267.75 & 737.6 & $1.113 \times 10^{-9}$ & 0.451 & 9.59 \\
\hline & 323.16 & $3.161 \times 10^{8}$ & 267.75 & 737.6 & $2.734 \times 10^{-10}$ & 0.45 & 17.28 \\
\hline & 343.16 & $4.802 \times 10^{8}$ & 288.39 & 761.1 & $4.02 \times 10^{-14}$ & 0.456 & 12.45 \\
\hline \multirow[t]{2}{*}{$\begin{array}{c}\text { CBZ-N-Aspartic } \\
\text { Acid }\end{array}$} & 333.16 & $4.903 \times 10^{8}$ & 288.39 & 761.1 & $5.928 \times 10^{-15}$ & 0.46 & 18.78 \\
\hline & 323.16 & $5.007 \times 10^{8}$ & 288.39 & 761.1 & $7.657 \times 10^{-16}$ & 0.462 & 9.56 \\
\hline
\end{tabular}


Table 4. The coefficients of the equation Yu et al. 1994 model for the correlation of the solubility of the derivatized amino acids.

\begin{tabular}{|c|c|c|c|c|c|c|c|}
\hline & \multirow{2}{*}{ Compound } & \multicolumn{6}{|c|}{ Coefficients of Model } \\
\hline & & C0 & C1 & C2 & C3 & C4 & C5 \\
\hline 1 & N-CBZ-valine & $9.62 \mathrm{E}-05$ & $2.74 \mathrm{E}-07$ & $-1.6 \mathrm{E}-09$ & $4.35 \mathrm{E}-08$ & $-1.2 \mathrm{E}-05$ & $6.08 \mathrm{E}-08$ \\
\hline 2 & N-CBZ-proline & 0.000136 & $-1.2 \mathrm{E}-05$ & $4.07 \mathrm{E}-08$ & $-5.2 \mathrm{E}-09$ & $2.64 \mathrm{E}-05$ & $-1.5 \mathrm{E}-07$ \\
\hline 3 & N-CBZ-aspartic acid & 0.000508 & $-7.2 \mathrm{E}-06$ & $-6.2 \mathrm{E}-09$ & $2.36 \mathrm{E}-07$ & $-7.6 \mathrm{E}-06$ & $-3 E-07$ \\
\hline
\end{tabular}

NCBZ-valine

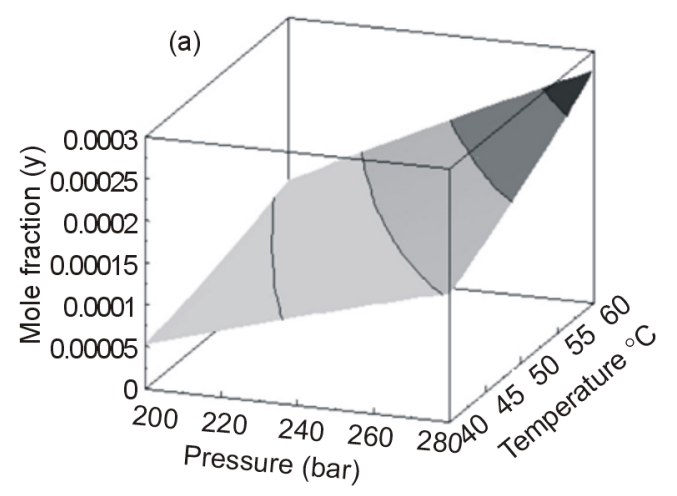

N-CBZ-proline

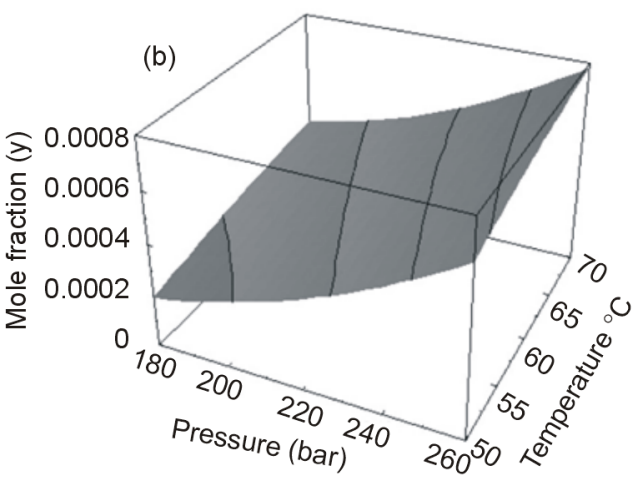

N-CBZ-aspartic acid

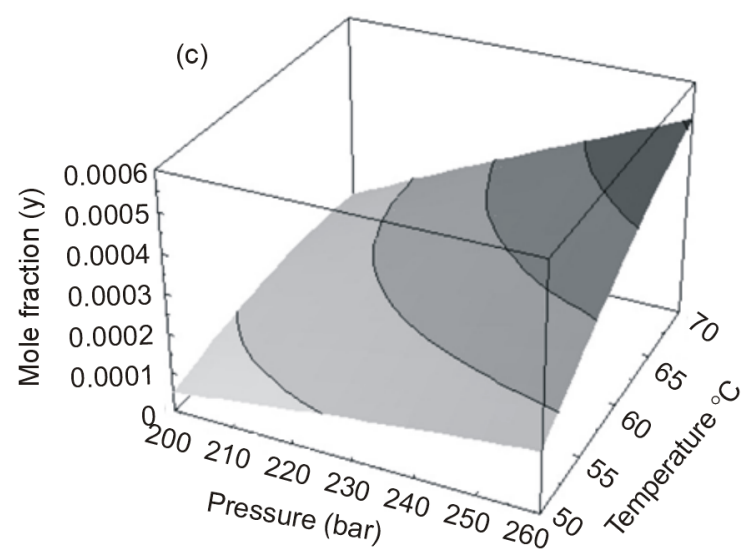

Figure 1. Model plot obtained using Yu model showing effect of pressures and temperatures on solubility of amino acids (a) N-CBZ valine; (b) N-CBZ-proline and (c) N-CBZ-aspartic acid in supercritical $\mathrm{CO}_{2}$.

The Gordillo model based coefficients for the Equation (5.1) of the various parameters of correlated solubilities of the dervatized amino acids as predicted using excel software, is provided in Table 5, the \% AARD as calculated by the Equation (3.2) for N-CBZ-valine is 0.245, while the regression statistical analysis showed R square 0.997, standard error 0.0369 and $F$ significance 4.14E-10, the p-values are less than 0.05 showing strong significance of the fit. For N-CBZ-proline the \%AARD as calculated by the Equation (3.2) is 1.067, while the regression statistical analysis showed R square 0.967 , standard error 0.0369 and $\mathrm{F}$ significance $4.13 \mathrm{E}-5$, the pvalues are less than 0.05 showing strong significance of the fit. For N-CBZ-aspartic acid the \%AARD as calculated by the Equation (3.2) is 1.144, while the regression statistical analysis showed R square 0.982, standard error 0.1705 and F significance 0.000266, the p-values are less than 0.05 showing strong significance of the fit. Figure 2 provide the graphical values of y for different temperatures and pressures for N-CBZ-valine, proline and aspartic acid. Table 6 provides values for correlation of the solubility of said compounds by both the Yu and Gordillo models. It is clearly observed that out of the models the empirical model Gordillo (2004) is observed for a better fit when compared to SRK model of correlation of solubility of the CBZ-N-amino acids. 

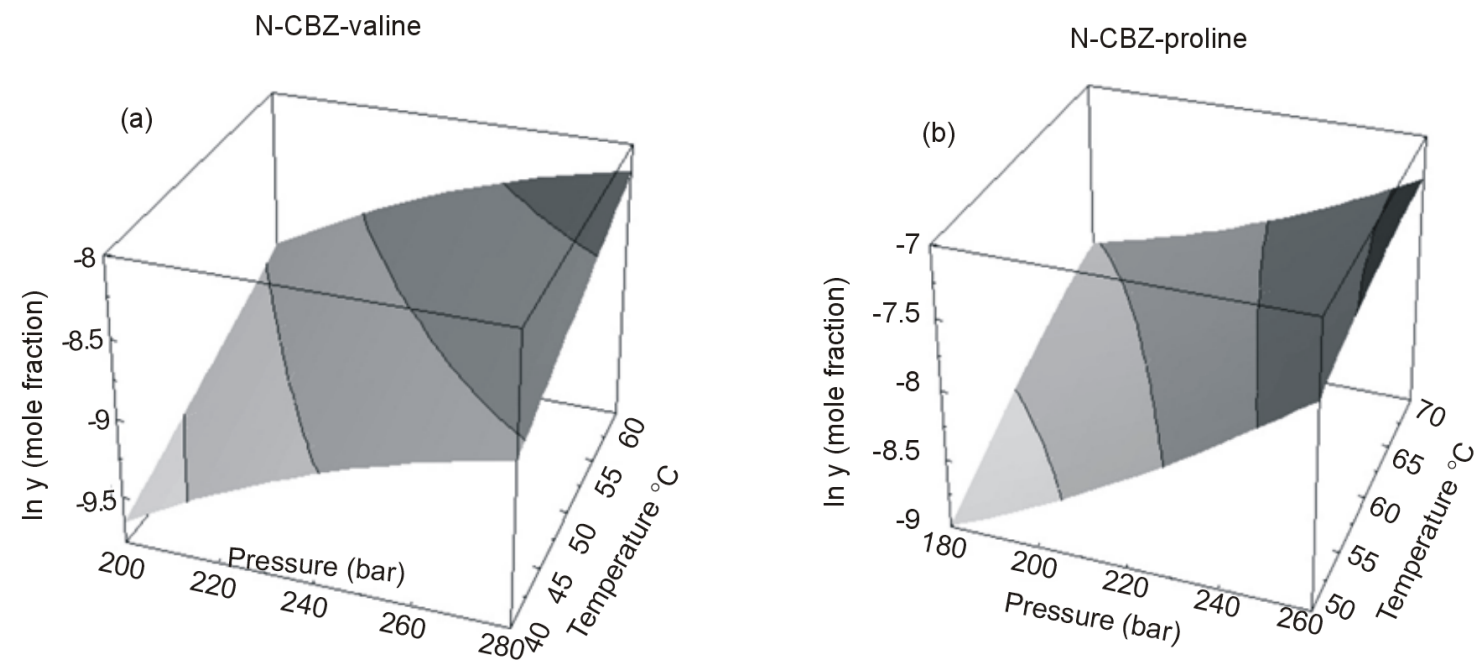

N-CBZ-aspartic acid

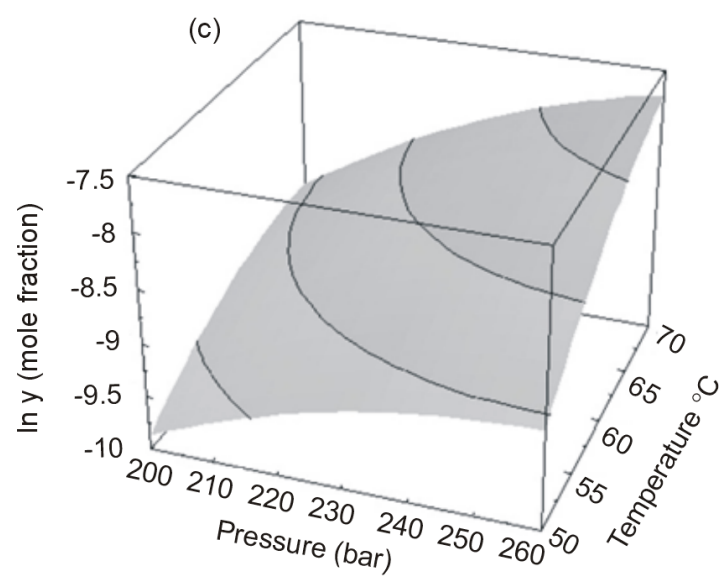

Figure 2. Model plot obtained using Gordillo and co-workers showing effect of pressures and temperatures on solubility of amino acids (a) N-CBZ valine; (b) N-CBZ-proline and (c) N-CBZ-aspartic acid in supercritical $\mathrm{CO}_{2}$.

Table 5. The coefficients of the equation Gordillo and coworker, 2004 model for the correlation of the solubility of the derivatized amino acids.

\begin{tabular}{rccccccc}
\hline & \multirow{2}{*}{ Compound } & \multicolumn{7}{c}{ Coefficients of Model } \\
\cline { 3 - 8 } & & D0 & D1 & D2 & D3 & D4 & D5 \\
\hline 1 & N-CBZ-valine & -17.2038 & 0.046064 & $-7 \mathrm{E}-05$ & $-2.8 \mathrm{E}-05$ & 0.031399 & $5.99 \mathrm{E}-05$ \\
2 & N-CBZ-proline & -16.9011 & 0.009473 & $5.87 \mathrm{E}-05$ & -0.00034 & 0.180687 & -0.00067 \\
3 & N-CBZ-aspartic acid & -27.836 & 0.089386 & -0.00022 & 0.000502 & 0.177329 & -0.002 \\
\hline
\end{tabular}

Table 6. Correlation of the experimental solubility to the predicted models of both Yu et al. and Gordillo models.

\begin{tabular}{ccccc}
\hline (bar) & $\left({ }^{\circ} \mathrm{C}\right)$ & N-CBZ Valine & N-CBZ Proline & N-CBZ Aspartic Acid \\
\hline Gordillo, 1999 & \% AARD & 0.245 & 1.067 & 1.144 \\
& R square & 0.997 & 0.976 & 0.965 \\
& Standard Error & 0.0369 & 0.1448 & 0.1705 \\
Yu, 1994 & \% AAD & 2.04 & 8.17 & 10.96 \\
& R square & 0.997 & 0.989 & 0.979 \\
& Standard Error & $4.06 \times 10^{-6}$ & $3.23 \times 10^{-5}$ & $2.74 \times 10^{-5}$ \\
\hline
\end{tabular}




\section{Summary and Conclusion}

An attempt was made on correlation of the experimental solubility of the derivatized N-CBZ amino acids using theoretical models based on SRK-EOS with mixing rules proposed by Soave and empirical models proposed by Yu et al. (1999) and Gordillo (2004) using software. Soave modified Redlich-Kwong EOS based showed varied \% AARD for the critical properties arrived by group contribution methods as high as $59 \%$ for N-CBZ-valine, while for N-CBZ-proline and N-CBZ-Aspartic acid it is reasonable limits of $<20 \%$. Between the models $\mathrm{Yu}$ and Gordillo, the Yu model has an \% AARD up to 12\%, while the best fit was observed using Gordillo empirical model \% AARD up to $1.2 \%$. Hence, it can be concluded that this model can be effectively used for and prediction of experimental solubility of naturally occurring biologically active compounds that are generally more polar.

\section{Acknowledgements}

Mr. Pravin Gadkari acknowledges the CSIR, New Delhi for the award of the Senior Research Fellowship. Directors of CSIR-CFTRI and CSIR-CLRI are acknowledged for their encouragement and support for this work.

\section{References}

[1] Udaya Sankar, K. (1993) Supercritical Fluid Carbon Dioxide Technology for Extraction of Spices and Other Value Bio-Active Compounds. In: Rizvi, S.S.H., Ed., Chapter 12: Supercritical Fluid Processing of Food and Bio-Materials, Black Academic and Professional, Glasgow, 155-167.

[2] Cooper, A.I. (2000) Polymer Synthesis and Processing Using Supercritical Carbon Dioxide. Journal of Materials Chemistry, 10, 207-234. http://dx.doi.org/10.1039/a906486i

[3] Gadkari, P.V., Balarman, M. and Kadimi, U.S. (2013) Polyphenols from Fresh Frozen Tea Leaves (Camellia assamica L.,) by Supercritical Carbon Dioxide Extraction with Ethanol Entrainer-Application of Response Surface Methodology. Journal of Food Science and Technology. http://dx.doi.org/10.1007/s13197-013-1085-9

[4] Udaya Sankar, K. and Manohar, B. (1999) Supercritical Carbon Dioxide Extraction Technology in the Production of High Value Bioactive Compounds-Global Perspectives. In: Trends in Food Science and Technology—Proceedings of the Technical Sessions of 4th International Food Convention-IFCON-98, Association of Food Scientists and Technologists (India), 223-236.

[5] Brunner, G. (2005) Supercritical Fluids: Technology and Application to Food Processing. Journal of Food Engineering, 67, 21-33. http://dx.doi.org/10.1016/j.jfoodeng.2004.05.060

[6] Vazquez, E., Giacalone, F. and Prato, M. (2013) Non-Conventional Methods and Media for the Activation and Manipulation of Carbon Nanoforms. Chemical Society Reviews, 43, 58-69. http://dx.doi.org/10.1039/c3cs60164a

[7] Reddy, S.N. and Madras, G. (2011) Solubilities of Benzene Derivatives in Supercritical Carbon Dioxide. Journal of Chemical and Engineering Data, 56, 1695-1699. http://dx.doi.org/10.1021/je100863p

[8] Vedaraman, N., Brunner, G., Srinivasa Kannan, C., Ramabrahmam, B.V. and Rao, P.G. (2004) Solubility of N-CBZ Derivatised Amino Acids in Supercritical Carbon Dioxide. Journal of Supercritical Fluids, 30, 119-125. http://dx.doi.org/10.1016/j.supflu.2003.07.005

[9] Santiago, J.M. and Teja, A.S. (1999) The Solubility of Solids in Supercritical Fluids. Fluid Phase Equilibria, 158-160, 501-510. http://dx.doi.org/10.1016/S0378-3812(99)00154-5

[10] Bartle, K.D., Clifford, A.A., Jafar, S.A. and Shilstone, G.F. (1991) Solubilities of Solids and Liquids of Low Volatility in Supercritical Carbon Dioxide. Journal of Physical and Chemical Reference Data, 20, 713.

[11] Yu, Z.R., Singh, B. and Rizvi, S.S.H. (1994) Solubilities of Fatty Acids, Fatty Acid Esters, Triglycerides, and Fats and Oils in Supercritical Carbon Dioxide. Journal of Supercritical Fluids, 7, 51-59. http://dx.doi.org/10.1016/0896-8446(94)90006-X

[12] Chrastil, J. (1982) Solubility of Solids and Liquids in Supercritical Gases. The Journal of Physical Chemistry, 86, 3016-3021. http://dx.doi.org/10.1021/j100212a041

[13] Gordillo, M.D., Blanco, M.A., Molero, A. and de la Ossa, E.M. (1999) Solubility of the Antibiotic Penicillin G in Supercritical Carbon Dioxide. Journal of Supercritical Fluids, 15, 183-190. http://dx.doi.org/10.1016/S0896-8446(99)00008-X

[14] Tang, Z., Jin, J.S., Zhang, Z.T. and Liu, H.T. (2012) New Experimental Data and Modeling of the Solubility of Compounds in Supercritical Carbon Dioxide. Industrial and Engineering Chemistry Research, 51, 5515-5526. http://dx.doi.org/10.1021/ie2016224 
[15] Ghosh, P. (1999) Prediction of Vapor-Liquid Equilibria Using Peng-Robinson and Soave-Redlich-Kwong Equations of State. Chemical Engineering Technology, 22, 379-399. http://dx.doi.org/10.1002/(SICI)1521-4125(199905)22:5<379::AID-CEAT379>3.0.CO;2-Q

[16] Klincewicz, K.M. and Reid, R.C. (1984) Estimation of Critical Properties with Group Contribution Methods. AIChE Journal, 30, 137-142. http://dx.doi.org/10.1002/aic.690300119

[17] Manohar, B. and Udaya Sankar, K. (2011) Prediction of Solubility of Psoralea corylifolia L. Seed Extract in Supercritical Carbon Dioxide by Equation of State Models. Theoretical Foundations of Chemical Engineering, 45, 409-419. http://dx.doi.org/10.1134/S0040579511040087

[18] Edalat, M., Bozar-Jomehri, R.B. and Mansoori, G.A. (1993) Generalized Equations Predicts Vapour Pressure of Hydrocarbons. Oil and Gas Journal, 1, 39-40.

[19] McHugh, M.A. and Krukonis, V.J. (1994) Supercritical Fluid Extraction: Principles and Practice. Butterworth-Heinemann, Boston.

[20] Liang, J.H. and Yeh, A.-I. (1991) Process Conditions for Separating Fatty Acid Esters by Supercritical $\mathrm{CO}_{2}$. Journal of the American Oil Chemists Society, 68, 687-692. http://dx.doi.org/10.1007/BF02662298

[21] Baslingappa, S.S., Manohar, B., Nagesha, G.K. and UdayaSankar, K. (2001) Enrichment of Tocopherol from Deodourized Distillate (DOD) by Supercritical Fluid Carbon Dioxide. Indian Chemical Engineer, 43, 283-287. 


\section{Nomenclature}

$\begin{array}{ll}a, b & \text { EOS mixture parameter } \\ k_{i j}, n_{i j} & \text { binary interaction parameter } \\ P & \text { pressure } \\ P_{c} & \text { critical pressure } \\ R & \text { universal gas constant } \\ T & \text { temperature } \\ T_{C} & \text { critical temperature } \\ T_{B} & \text { normal boiling point temperature } \\ M_{w} & \text { molecular weight of the compound } \\ \Delta T_{L} & \text { group Contributions for temperature in Lydersen equation } \\ \Delta V_{L} & \text { group Contributions for volume in Lydersen equation } \\ V_{c} & \text { critical volume } \\ \Delta B_{J} & \text { group Contributions for boiling point } \\ P_{r}^{s} & \text { reduced vapor pressure } \\ f_{2}^{s} & \text { fugacity of solute in the solid phase } \\ f_{2}^{v} & \text { fugacity of solute in the gas phase } \\ v, V & \text { molar volume } \\ y, y_{2} & \text { mole fraction in supercritical phase }\end{array}$

\section{Greek Letters}

$\begin{array}{ll}\varphi & \text { fugacity coefficient } \\ \omega & \text { acentric factor } \\ \rho & \text { density }\end{array}$

\section{Subscripts}

$\begin{array}{ll}\mathrm{c} & \text { critical } \\ \mathrm{i}, \mathrm{j} & \text { component indices } \\ \text { cal } & \text { calculated value } \\ \text { pre } & \text { predicted value }\end{array}$

\section{Superscripts}

$\begin{array}{ll}\text { sat } & \text { saturated value } \\ \text { sub } & \text { sublimation }\end{array}$

\section{Abbreviations}

AARD

EOS

averageabsolute relative deviation

SRK

equation of state

SCF

Soave-Redlich-Kwong

$\mathrm{CO}_{2}$

Supercritical fluid

Carbon dioxide 
Scientific Research Publishing (SCIRP) is one of the largest Open Access journal publishers. It is currently publishing more than 200 open access, online, peer-reviewed journals covering a wide range of academic disciplines. SCIRP serves the worldwide academic communities and contributes to the progress and application of science with its publication.

Other selected journals from SCIRP are listed as below. Submit your manuscript to us via either submit@scirp.org or Online Submission Portal.
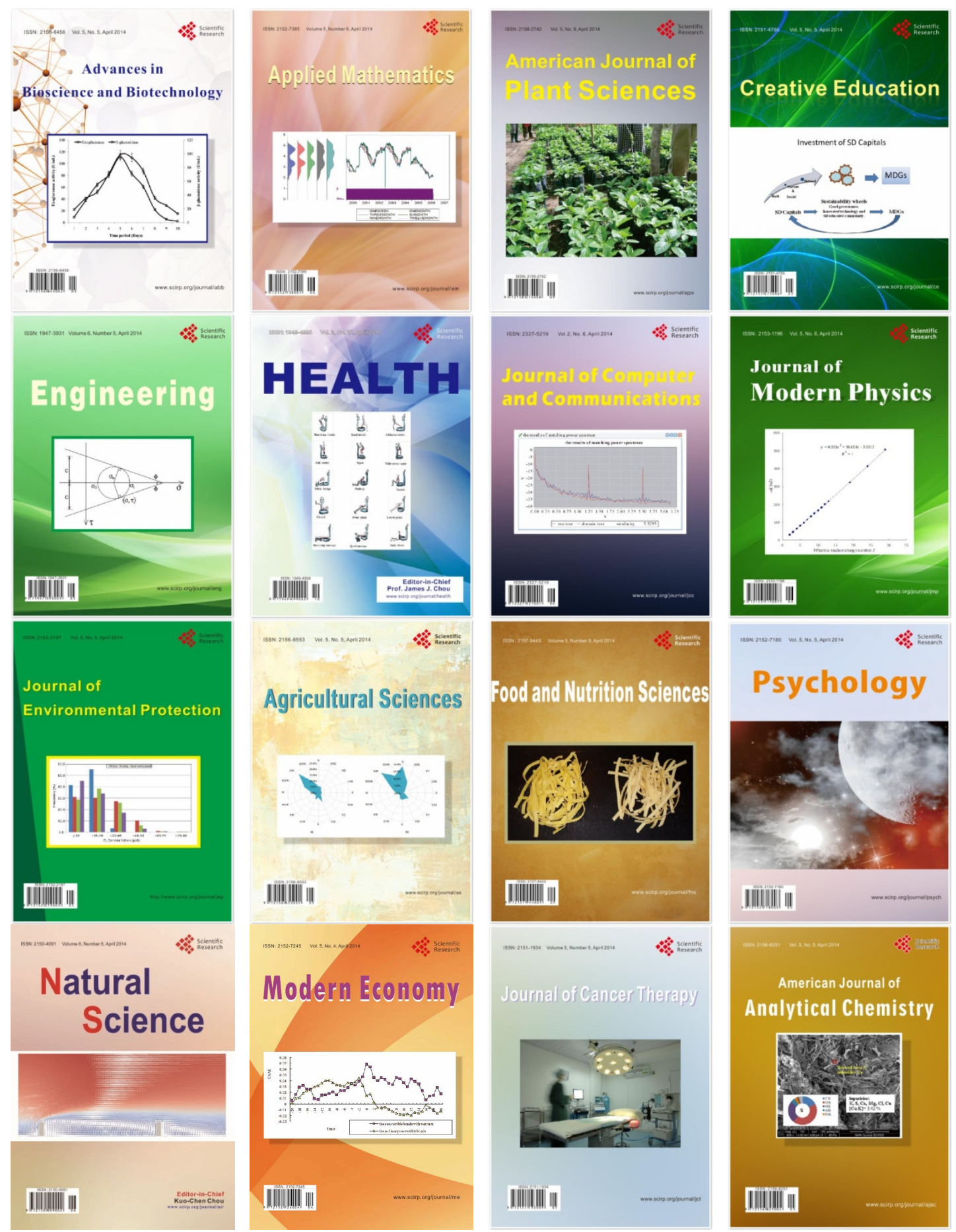